\title{
The Role of Manipulatives in Enhancing Pupils' Understanding on Fraction Concepts
}

\author{
Jamilah Yusof \\ Sultan Hassanal Bolkiah Institute of Education \\ Universiti Brunei Darussalam \\ Sarimah Lusin \\ Ministry of Education
}

\begin{abstract}
Zoltán Dienes and Josef Perner's work [24] convinced many researchers that the use of various representations of a concept, or 'multiple embodiments,' were needed to support pupils' understanding. Piaget [4] suggested that young children do not have the mental maturity to grasp abstract mathematical concepts presented in words or symbols alone and they need many experiences with concrete materials and drawings for learning to occur. Bruner [1,2] suggested that children demonstrate their understandings in three stages of representation: enactive (the role of physical objects), iconic and symbolic. Skemp's theories [22] supported the belief that pupils' early experiences and interactions with physical objects formed the basis for later learning at the abstract level. Based on theories of cognition and the social construction of knowledge [23], more recent research by Cobb [3] discusses cultural tools like hundreds boards, showing the complicated relationship between manipulatives and sociocultural perspectives. Current research in mathematics education views pupils as active participants who construct knowledge by reorganizing their current ways of knowing and extracting coherence and meaning from their experiences [8], [9], [17], [19]. The impact of theories and research connecting pupils' actions on physical objects with mathematical learning has had an important influence on the emergence and use of manipulative in primary school classrooms.

This paper reports on a study which examined how much manipulatives have been used in the teaching of fractions for Year 5 pupils in Brunei Darussalam. The purpose was to determine whether using manipulatives to teach fractions could promote active learning and enhance the achievement among those pupils. This small scale study used both qualitative and quantitative data obtained from the pre and post tests, interviews and classroom observation to determine the effectiveness of using
\end{abstract}

manipulatives as implemented in the teacherdesigned intervention lessons. The paper concludes with some recomendations on how different types of manipulatives can be used in their effective ways to promote pupils' understanding of fraction concepts.

\section{Introduction}

Fractions teaching have embraced attention of mathematics teachers and educators worldwide due to the fact that many learners seem to have problems in understanding the concept of fractions [5], [13], [14], [16]. Pupils need to be actively involved in their learning and manipulate objects in their surrounding so that they can generate better understanding of mathematical concepts. Thus, in the teaching and learning of fractions, ideally, pupils should be given opportunities to explore the fractions concept through hands-on experiences, share their ideas among themselves and more importantly to learn fraction concepts with the help of appropriate manipulatives.

Heddens [11] defined manipulative materials as concrete models that involve mathematical concepts, appeal to several senses including the socio-cultural needs that can be touched and moved around by the learners [6].

Mathematics educators around the world have found that mathematics is better learned, and therefore should be taught, by students experiencing it through manipulatives [20]. According to them, the two main reasons for teachers not using manipulatives in their mathematics classrooms were that teachers were uncertain of how to use the manipulatives, and they felt that manipulative instruction was inappropriate for students above the fourth grade. Sherman and Richardson [18] reported these reasons for teachers not using manipulatives: being unfamiliar and uncomfortable with the materials themselves, concerns about time constraints, possible discipline problems, availability of manipulatives and their cost. 
Hatfield reported that using manipulatives approach to mathematics instructions requires the knowledge, skills, and experiences necessary to respond to students who are learning in this environment. This is clearly reasonable as supported by Hougas [12] who shared that studies on manipulatives use revealed that some of the main reasons why teachers do not use manipulatives is that the teachers do not feel that manipulatives benefit the teaching of mathematics and that the teachers need instruction on the effective use of manipulatives. This implies that teachers need to be well versed and confident in using the varieties of manipulatives in appropriate context and non-threathening not only to the students but the teachers as well.

As reported by a local researcher, Giok [7] that teachers lacked skills in using manipulatives effectively, and that they used manipulatives for demonstration and explanation purposes. She further reported that pupils were not given opportunities to manipulate concrete materials due to limited supply of materials. The findings from her study also revealed that the factors influencing teachers' choice of manipulatives materials in their teaching were time factor, class size, availability of resources and teacher's pedagogical skills.

Virtual manipulatives are also widely available through the web-page resources. Moyer, Bolyard, and Spikell [15] defined a virtual manipulative as an interactive, Web-based visual representation of a dynamic object that presents opportunities for constructing mathematical knowledge. The key is for students to be able to construct meaning on their own by using the mouse to control physical actions of objects by sliding, flipping, turning, and rotating them.

Virtual manipulatives have a range of characteristics, such as pictorial images only, combined pictorial and numeric images, simulations, and concept tutorials, which include pictorial and numeric images with directions and feedback. Currently, virtual manipulatives are modeled after concrete manipulatives such as base ten blocks, coins, pattern blocks, tangrams, spinners, rulers, fraction bars, algebra tiles, geoboards, and geometric plane and solid figures, and are usually in the form of Java or Flash applets.

Lett [14] reported that active hands-on participation with mathematical experiences promotes understanding of concepts that will benefit students throughout their lives. Therefore, providing opportunities for pupils to explore and investigate mathematical ideas with concrete materials is a crucial aspect of learning mathematics. However, this was what appeared to be lacking in the classroom observations data for this study. Teachers did not give opportunities for pupils to explore the use of fractions manipulatives before they do group task.
Therefore, in this study, manipulatives are defined as objects designed to represent explicitly and concretely mathematical ideas that are abstract. They have both visual and tactile appeal and can be manipulated by learners through hands-on experiences [15].

Since this study had a focus on fraction work, the researchers specifically used the virtual manipulatives that utilized the pictorial image manipulation. This virtual manipulatives portrayed the area model of fraction manipulatives that simulated the addition of fraction with related denominators. The reason for choosing this virtual manipulatives was that it saved time in changing the fraction partitions for different equivalent fractions in order to illustrate and demonstrate the addition of related fractions. Furthermore, pupils can have more chances of creating a number of equivalent fractions for particular fractions in much shorter time compared to the paper cutting and paper folding trial and errors.

\section{Methodology}

In this study, the performance of 44 Year 5 pupils from a government primary school in doing fractions work with the help of selected manipulatives was examined. The purpose of this study was to determine whether using different types of manipulatives to teach fractions could promote better and active learning and to further enhance the attainment of Year 5 pupils in doing fraction works.

The study was guided by the following Research Questions:

Research Question 1: What are the current teaching strategies used by Year 5 mathematics teachers in teaching fractions?

Research Question 2: Do pupils show higher attainment in doing fraction work after receiving treatment from the intervention lessons used by the researcher?

A Paper and pencil pre-test was administered to two classrooms identified earlier, as being taught using manipulatives only during the demonstrations and explanations of fraction concepts, but those pupils were not allowed to practise the use of manipulatives in solving fractions work during group task activities. The pre-test was intended to investigate the pupils' performance in fraction works after they were being taught by their actual teacher during the classroom observations.

The researchers developed intervention lessons based on the classroom observations and the pre-test, with the aim to examine whether the intervention strategies that wereused by the researchers could outdo the teaching strategies used by the teachers involved in this study, in terms of pupils' active learning and pupils' attainment, which was measured using written post-test. 
The researchers used the results from the pre- and post-tests to determine whether the intervention lessons could have provided some impact on the pupils' performance in doing fraction works.

To support the qualitative data,the researchers observed seven fraction lessons from four government primary schools with the help of observation checklists. Lesson observations were video-recorded with teachers' permission. Based on the observations, two classrooms were selected for the intervention lessons. The two classrooms selected were those classes being observed as having fraction lessons where the use of manipulatives were partially absent or not evident in a cooperative learning settings, i.e., the teachers only used manipulatives for explanation and demonstration, but not during group tasks activities.

All the pupils involved in the intervention lessons were given pre-test before being introduced to the intervention lessons that the researchersdesigned. After the intervention lessons had been carried out, a post-test was given to the same cohort of pupils who did the pre-test.

In addition, validated teachers' questionnaires were distributed to all upper primary mathematics teachers from the Brunei 1 zone. The total number of upper primary mathematics teachers involved in the study was 56. To strengthen this study, the researchers interviewed six of the teachers who were involved in answering the teacher questionnaires. The selection of teachers was based on their willingness to be involved in the interview.

\section{Results and Discussion}

The researchersused SPSS Version 16 to analyze the data in order to answer the following three research questions:

Research Question 1: What are the current teaching strategies used by Year 5 mathematics teachers in teaching fractions?

In answering this Research Question 1, data from both the classroom observations and interview show that upper primary mathematics teachers practised pupil-centred approach to build on pupils' ideas on the teaching of fractions. Opportunities were given for pupils to use discovery or exploration learning to construct their own knowledge on fractions concepts. They were always practising the use of cooperative learning where pupils were actively engaged during group work and pupils showed positive interactions among themselves as well as with their teachers. The majority of the teachers preferred to use mixed ability groupings and pair work in order to provide cooperative learning environment in the teaching and learning of fractions.

Though most of the teachers were using fractions manipulatives, not all of them allowed pupils to practise the use of manipulatives in solving the group tasks cooperatively among themselves. There were still a small percentage of teachers who limited the use of fraction manipulatives for teachers' demonstration and explanation purposes only. This was more evident in the two identified classes that were given the intervention lessons.

The most commonly used fraction manipulatives were fractions shapes and fractions strips. The majority of teachers provided opportunities for pupils to familiarize themselves using the manipulatives before proceeding to group work, but only through teachers' demonstrations. Many teachers did not give opportunities for their pupils to explore the use of fraction manipulatives before they do group tasks. Teachers occasionally showed tendencies to dominate instruction and facilitate whole group interactions.

Nevertheless, teachers also consistently provided guidance for groups that encountered problems in solving the group tasks and provided feedback from pupils' questions by stimulating their thinking. It was observable that all fraction manipulatives used were able to develop pupils' motivations and interests in solving group tasks and created understanding on the concepts related to fractions.

In summary, most teachers observed were teaching fractions in active and interactive approaches though the intensity level of the approaches needsto be increased. It is important for teachers to provide opportunities for pupils to practise hands-on manipulation of objects in order to grasp the concepts of fractions easily. This is what was lacking during the lesson observation of the two classes that were given intervention lessons. The learning would be much meaningful and could create better understanding if pupils were given opportunities to use manipulatives in solving their group tasks.

Research Question 2: Do pupils show higher attainment in doing fraction work after receiving treatment from the intervention lessons used by the researcher?

Data collected from the pre and post-testswere used to answer Research Question 2 in terms of means score differences for the pupils' performance between the pre- and post-tests by computing the $\mathrm{T}$ tests.

A paired-sample- $t$-test was conducted on the preand post-tests for the overall performance of the pupils. The $t$-test for the overall performance of the pupils in four operations of Fractions was used to determine the effect of the intervention lessons towards the pupils' attainment in fraction work. Data was further analyzed to indicate any significant difference in terms of pupils' achievement scores in the post-test as compared to the pre-test. 
Table 1. Paired sample t-test result and effect size for pre-test and post-test on pupils' $(\mathrm{N}=44)$

\begin{tabular}{|c|c|c|c|c|c|c|c|c|}
\hline Concept & $\begin{array}{l}\text { Pre- } \\
\text { test } \\
\text { Mea } \\
\text { n } \\
\text { Scor } \\
\text { e } \\
\left(M_{I}\right) \\
\end{array}$ & $\begin{array}{l}\text { Post } \\
\text {-test } \\
\text { Mea } \\
\text { n } \\
\text { Scor } \\
\text { e } \\
\left(\mathrm{M}_{2}\right) \\
\end{array}$ & $\begin{array}{l}\text { Pre-test } \\
\text { Standar } \\
\mathrm{d} \\
\text { Deviatio } \\
\mathrm{n}\left(S D_{l}\right)\end{array}$ & $\begin{array}{l}\text { Post-test } \\
\text { Standar } \\
\text { d } \\
\text { Deviatio } \\
\mathrm{n}\left(S D_{2}\right)\end{array}$ & $\begin{array}{l}t- \\
\text { valu } \\
\text { e }\end{array}$ & df & 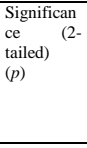 & $\begin{array}{l}\text { Effec } \\
t \\
\text { Size } \\
\text { (d) }\end{array}$ \\
\hline $\begin{array}{l}\text { Addition of } \\
\text { Related } \\
\text { Fractions }\end{array}$ & 5.18 & 7.89 & 3.66 & 3.21 & 4.94 & $\begin{array}{l}4 \\
3\end{array}$ & $.000 *$ & 0.8 \\
\hline $\begin{array}{l}\text { Subtraction } \\
\text { of Related } \\
\text { Fractions }\end{array}$ & 3.77 & 6.09 & 3.37 & 3.64 & 5.16 & $\begin{array}{l}4 \\
3\end{array}$ & $.000 *$ & 0.7 \\
\hline $\begin{array}{l}\text { Multiplicati } \\
\text { on of } \\
\text { Fraction } \\
\text { with Whole } \\
\text { Number }\end{array}$ & 6.34 & 9.32 & 3.24 & 2.17 & 5.91 & $\begin{array}{l}4 \\
3\end{array}$ & $.000^{*}$ & 1.1 \\
\hline $\begin{array}{l}\text { Division of } \\
\text { Fractions } \\
\text { with Whole } \\
\text { Number }\end{array}$ & 6.39 & 7.66 & 2.53 & 1.74 & 3.55 & $\begin{array}{l}4 \\
3\end{array}$ & $.001 *$ & 0.6 \\
\hline
\end{tabular}

*Significant at $\mathrm{p}<.05$

Table 1 shows the pupils' performance in the four sub-topics of fractions. The result shows that there were significant increase in the mean scores from pre-test to post-test, for all the four sub-topics of fractions. The increase in the performance was all significant at $\mathrm{p}<.05$ for the four sub-topics of fractions. The values of the effect size for all the four sub-topics of fractions were in the category ranging from medium to large effect size values (medium effect size values for $d=6$ and $d=0.7$; and large effect size values for $d=0.8$ and $d=1.1$ ). This suggests that the intervention lessons did contribute a significant improvement on the pupils' attainment in all the subtopics of fractions being tested in the post-test.

Therefore in answering this Research Question 2, the intervention lessons have shown significant positive effects on the performance of pupils in all the four subtopics of fractions being investigated; Addition of Related Fractions, Subtraction of Related Fractions, Multiplication of Fractions with Whole Numbers and Division of Fractions with Whole Numbers.

Among all these four sub-topics of fractions, the most highly significant improvement in the pupils' attainment in the post-test (after intervention lessons) is shown in the sub-topics of Multiplication of Fractions with Whole Numbers as compared to the pre-test (before intervention lessons), with an increase in mean score from 6.34 in the pre-test to 9.32 in the post test and a large effect size $(d=1.1)$.

The overall analysis of pupils' pre- and post-tests indicates that the intervention lessons had successfully improved the pupil's overall attainment in fraction works. There was a strong indication that the intervention lessons had been effective in helping pupils to attain a better understanding on the four operations of fractions. However, there was no statistically significant difference between boys' and girls' attainment in fraction works, where the increase in mean score $\left(M_{l}=22.38\right.$ to $M_{2}=30.72$ for boys and $M_{1}=20.33$ to $M_{2}=31.40$ for girls) from pre- test to post test, with $\mathrm{p}>.05$ for both the pre- and post-tests. This shows that both boys and girls did equally well in the pre and post-tests.

\section{Conclusion}

The outcome of the study suggests that upper primary school mathematics teachers practised pupilcentered teaching approach where they built on pupils' ideas and allowed pupils to use discovery learning or exploration learning to construct their own knowledge of fractions concepts. They were always practising the use of cooperative learning strategies where pupils were actively engaged during group work and pair works and pupils often showed positive interactions among themselves and with their teachers. From the classroom observation data, most teachers were using manipulatives when they were teaching fractions. However, it was indicated that some teachers still limited the use of fraction manipulatives for teachers' demonstration and explanation purposes only.

Supporting data from the teachers' interview indicated that there was a strong indication that the majority of teachers found the teaching of fractions to be rather difficult. Nevertheless, it was encouraging that they also admitted that they need more professional development focusing on the teaching and learning of fractions.

Although many teachers were enthusiastic to use manipulatives to teach fractions, especially in a cooperative learning environment, due to several constraints, they were reluctant to allow their pupils to practise the use of fraction manipulatives during cooperative group tasks. The main constraints to the use of fractions manipulatives in cooperative learning setting, as reported by teachers, were timeconsuming and resources-availability. With more exposure on the benefits of using manipulatives in the teaching and learning of fractions through teachers' professional development, this skeptical view can hopefully be remedied.

Fraction manipulatives were readily available at most primary schools, but were only limited for the use of teachers' demonstration and explanation and not sufficient for the use of solving cooperative tasks. Teachers reported that they needed to make their own fractions manipulatives or even buy them in order to give opportunities for pupils to use fractions manipulatives for solving cooperative tasks. Therefore, there were observable evidences of minimal effective usage of fraction manipulatives being incorporated in cooperative learning environment.

Despites those constraints associated with the use of manipulatives to teach fractions in cooperative setting, there was a strong indication that teachers had positive beliefs towards the use of manipulatives 
in teaching fractions through cooperative learning setting.

Among the common views reported by teachers were that fractions manipulatives were able to provide opportunities for exploration learning through hands-on experiences, which helped pupils in the recognition and pictorial representations of fractional parts. Teachers further reported that cooperative learning could create enjoyment and help pupils develop better understanding on the concept of fractions. They believed that this learning strategy could create opportunities for pupils to share ideas and help each other's learning as well as developing mutual understanding. There was also strong indication that teachers perceived the use of manipulatives to teach fractions in cooperative learning is in line with the SPN21 curriculum framework because this strategy is pupil-centred, provide exploration of ideas and give opportunities for pupils to manipulate objects from their surroundings.

All the above criteria are also outlined in the SPN21 [21] book where it is stated "The teaching and learning process will be student-centred with students being actively engaged in learning both individually and in groups." Therefore, this confirms that the use of manipulatives to teach fractions in cooperative learning environment is indeed in line with SPN21 curriculum framework.

From the pre- and post-tests findings, there were significant positive effects on the performance of pupils in all the four subtopics of fractions being investigated in this study. The intervention lessons, which utilised the use of manipulatives to teach fractions in cooperative learning environment, were statistically producing highly significant improvement on the pupils' overall attainment in fraction works. There was highly significant improvement in the overall performance of pupils in post-test (after intervention lessons) as compared to the pre-test (before intervention lessons). This strongly suggests that pupils showed higher attainment in doing fraction works after receiving treatment from intervention lessons. There is a strong indication that the use of manipulatives to teach fractions in cooperative learning environment, as utilised in the intervention lessons, had been effective in helping pupils to attain a better understanding on the four operations of fractions.

The findings from this study concurred with Lett [14] who reported that active hands-on participation with mathematical experiences promotes understanding of concepts that will benefit students throughout their lives. Therefore, providing opportunities for pupils to explore and investigate mathematical ideas with concrete materials is one of the crucial aspects of learning mathematics. This was what, however, appeared to be lacking in the classroom observations data for this study. Teachers observed, did not give ample opportunities for pupils to explore the use of fractions manipulatives before they did group tasks.

In addition, this study was also in agreement with another researcher, Giok [7], who reported that some teachers lacked skills in using manipulatives effectively, and that they used manipulatives for demonstration and explanation purposes only. Further longitudinal researchwith a bigger sample is needed in order to investigate the long-term effect of manipulativesin the teaching and learning of fractions by following the same cohort of pupils over a year period.

\section{References}

[1]Bruner, J. (1960) The process of educationVintage, New York.

[2] Bruner, J. (1986) Actual Minds, Possible Worlds, Cambridge, MA: Harvard University Press.

[3] Cobb, P. (1995). Mathematical learning and smallgroup interaction: Four case studies. In P. Cobb \& H. Bauersfeld (Eds.), The emergence of mathematical meaning: Interaction in classroom cultures (pp. 25-129). Mahwah, NJ: Lawrence Erlbaum Associates.

[4] Piaget J (1952). The origins of intelligence in children. New York: International Universities press.

[5] Cramer, K \& Harry, A. (2002). Using manipulatives models to build number sense for addition of fractions. National Council of Teachers of Mathematics 2002 Yearbook: Making Sense of Fractions, Ratios and Proportions (pp. 41-48). Reston, VA: National Council of Teacher of Mathematics.

[6] Durmus, S., \&Karakirik E. (2006). Virtual manipulatives in mathematics education: A theoretical framework.The Turkish Online journal of Education Technology, 5(10), article 12.Retrieved on 24.03.2010.from the Worldwide Web: http://www.tojet.net/articles/5112.html.

[7] Giok, L.L. (2008). The use of manipulatives in teaching primary mathematics. Unpublished M.Ed. project thesis.Universiti Brunei Darussalam.

[8] Glasersfeld, E. von (1990). "Environment and Education.” In L.P. Steffe\& T. Wood (eds.), Transforming Children's Mathematics Education: International Perspectives, (pp. 200-215). Hillsdale, NJ: Lawrence Erlbaum.

[9] Glover J, Ronning R, Bruning R (1990). Cognitive psychology for teachers. New York: Macmilan

[10] Groff, P. (1996). The future of fractions.International Journal of Mathematics Education in Science and Technology, 25, $549-561$

[11] Heddens, J.W. (2005).Improving mathematics teaching by using manipulatives.In Durmus\& E. Karakirik (2006). Virtual manipulatives in mathematics education: A 
theoretical framework. The Turkish Journal of Educational Technology.5 (1).http://www.tojet.net/articles/5112.htm (Access date :24/03/2010)

[12] Hougas, L. (2003). Using manipulatives to teach fraction: A paper presented to Faculty of Viterbo University. In partial fulfillment for the Degree of Master of Arts in Education. Retrieved on 03.01.2010 from the Worldwide

Web:http://www.learningandteaching.orgResearchPaperH ougas.Pdf.

[13] Jamilah, Y. (2003). Mathematical errors in fraction works: A longitudinal study of primary level pupils in Brunei. Unpublished PHD dissertation.Curtin University of Technology. Australia.

[14] Lett, S. (2007). Using manipulatives materials to increase student achievement in mathematics.http//www.eric.ed.gov/ERICDocs/data/ericdo cs2sq1/content_storage_01/000001/9b/80/3a/47/0a.pdf.(Ac cess date on 06/04/2010 )

[15] Moyer, P.S. (2001). Are we having fun yet? How teachers use manipulatives to teach mathematics. Educational Studies in Mathematics, 2001, 47,175-197.

[16] Reimer, K., \& Moyer, P. (2005). Third graders learn about fractions using virtual manipulatives: A classroom study. Journal of Computers in Mathematics and Science Teaching, 24 (1), 5-25.

[17] Resnick, L. B. (1983). A developmental theory of number understanding. In H. P. Ginsburg (Ed.), Thedevelopment of mathematical thinking (pp. 109-151). New York: Academic Press.

[18] Sherman, H., \& Richardson, L., (1995). Elementary school teachers' beliefs and practices related to teaching mathematics with manipulatives. Educational Research Quarterly, June 1995, 18, 27 - 36.

[19] Simon, H. A. (1987/1995). Problem forming, problem finding, and problem solving in design. In A. Collen \& W. W.Gasparski (Eds.), Design and systems: General applications of methodology (Vol.3, pp. 245-257). New Brunswick,NJ: Transaction Publishers.

[20] Tooke, D.J., Hyatt, B., Leigh, M., Snyder, B., \&Borda, T., (1992). Why aren't manipulativesused in every middle school mathematics classroom? Middle School Journal, 24(3), 61-64.

[21] SPN21, (2009). The National Education System for the 21st Century SPN21.Ministry of Education. Negara Brunei Darussalam

[22] Skemp, R. (1987) The Psychology of Learning Mathematics,Lawrence Erlbaum Associates, Hillsdale, NJ

[23] Vygotsky, L. S. (1978). Mind in society: The development of higher psychological processes.(M. Cole, V. John-Steiner, S. Scribner, \& E. Souberman, Eds.). Cambridge, Massachusetts: Harvard University Press.
[24] ZoltánDienes\& Josef Perner (1999) A Theory of Implicit and Explicit Knowledge. Behavioral And Brain Sciences 22 (5):735-808. 